\title{
Upravljanje preduzećem u doba pandemije COVID-19: izazovi za preduzetnike, mala i srednja preduzeća
}

\section{Enterprise management in the age of pandemic COVID-19: challenges for entrepreneurs, small and medium enterprises}

\author{
Doc. dr Violeta Jovanović1* ${ }^{1 *}$ r Marija Nikolić Tošović ${ }^{2}$ \\ ${ }^{1}$ Fakultet za menadžment Zaječar, Park šuma Kraljevica bb. Zaječar, Srbija / \\ Faculty of Management Zaječar, Park šuma Kraljevica bb. Zaječar, Serbia \\ ${ }^{2}$ LUM Jean Monnet University, Faculty of Economics, Italy \\ *Autor za prepisku / Corresponding author \\ Rad primljen / Received: 14.12.2020, Rad prihvaćen / Accepted: 12.05.2021.
}

\begin{abstract}
Sažetak: Na proces poslovanja utiče veliki broj faktora, spoljašnjih i unutrašnjih. Neke od ovih faktora menadžeri mogu kontrolisati u potpunosti, a neke vrlo malo ili nimalo. Najmanju kontrolu menadžeri imaju nad faktorima okruženja. Značajan faktor okruženja sa kojim se trenutno susreću preduzeća, a koji utiče na sve sisteme i aspekte poslovanja i procese upravljanja kako velikim sistemima, tako i sektorom preduzetništva, malim i srednjim preduzećima, jeste pandemija virusa COVID-19. U radu se analiziraju izazovi sa kojim se susreću preduzetnici, mala i srednja preduzeća kao i promene koje je neophodno uneti u proces upravljanja preduzećem u doba pandemije. Za istraživanje uticaja COVID-19 na poslovanje kao i za istraživanje uticaja pandemije na proces upravljanja ovim privrednim sektorom korišćeni su sekundarni podaci iz internet izvora kao i publikacija objavljenih u naučnim časopisima tokom 2020. godine. Analize pokazuju da su krizom najteže pogođena novoosnovana preduzeća. Pad preduzetničkih aktivnosti, otpuštanje radnika i zatvaranje preduzeća uočava se kako na globalnom nivou tako i u Srbiji. Autori predlažu neophodno uvođenje novih poslovnih modela kao rešavnje problema koje je prouzrokovala pandemija, kao i rapidno angažovanje određenih veština i sposobnosti menadžera kako bi postojeće pretnje izazvane pandemijom COVID-19 pretvorili u šanse.
\end{abstract}

Ključne reči: upravljanje preduzećem, preduzetništvo, mala i srednja preduzeća (MSPP), pandemija COVID-19.

\begin{abstract}
A business is influenced by a large number of factors, external and internal. Some of these factors can be completely controlled by managers, while some very little or not at all. Managers have the least control over environmental factors. A significant environmental factor currently faced by companies, which affects all systems and aspects of business and management processes in large systems as well as in the enterprise sector, small and medium enterprises, is the COVID-19 pandemic. The paper analyzes the challenges faced by entrepreneurs, small and medium enterprises as well as the changes that need to be made in the process of enterprise management during the pandemic. Secondary data from Internet sources as well as publications published in scientific journals during 2020 were used to investigate the impact of COVID-19 on business as well as to investigate the impact of the pandemic on the management process of this economic sector. Analyzes show that newly established companies have been hardest hit by the crisis. The decline in entrepreneurial activities, layoffs and company closures can be seen both globally and in Serbia. The authors propose the necessary introduction of new business models as solutions to the problems caused by the pandemic, as well as the rapid engagement of certain skills and abilities of managers in order to turn the existing threats caused by the COVID-19 pandemic into opportunities.
\end{abstract}

Keywords: enterprise management, entrepreneurs, small and medium enterprises, COVID-19 pandemic.

${ }^{1}$ orcid.org/0000-0003-3624-4341, e-mail: violeta.jovanovic@fmz.edu.rs

${ }^{2}$ orcid.org/0000-0003-0231-257X, e-mail: mmarija.nnikolic@gmail.com 


\section{UVOD / INTRODUCTION}

Epidemija Covid-19 pojavila se u Kini krajem 2019. godine, a već početkom naredne godine proglašena je pandemija. Od tada je značajno uticala na svetsku ekonomiju i sve sektore života: zdrvastvo, obrazovanje, sve privredne delatnosti - proizvodne i uslužne. Ogroman uticaj pandemije usled karantinskih mera i zaključavanja država, očigledan je u svim sektorima privredne aktivnosti, te je virus postao ekonomski jednako „zarazan“ kao i medicinski (Vassileva et al., 2020). Zbog toga se širom sveta preduzimaju koraci na nivou preduzeća, kao i na pojedinačnim nivoima za suočavanje sa ovom krizom (Kuckertz et al., 2020).

Jedan od sektora koji je značajno pogođen pandemijom je preduzetništvo, mala i srednja preduzeća (MSPP). Preduzetnici su vitalni izvor ekonomije jedne zemlje. Podstiču ekonomiju uvođenjem inovativnih tehnologija, usluga, proizvoda i pružanjem novih mogućnosti i radnih mesta koja doprinose ekonomskom razvoju (Liu et al., 2020). Međutim, zbog preventivnih mera koje su vlade preduzele da ograniče i spreče prenos virusa, došlo je do ogromnih socijalnih i ekonomskih poremećaja u poslovanju, na različitim nivoima, od kojih su mala preduzeća i preduzetnici postali najranjiviji. Negativni uticaj primećen je na preduzeća širom sveta i većina novoformiranih preduzeća bila je primorana da otpusti svoje zaposlene, što je dovelo do problema kao što su široko rasprostranjena nezaposlenost, nedostatak produktivnosti i pad ekonomija. Covid-19 je takođe uticao na globalni lanac snabdevanja, što je generalno rezultiralo smanjenjem ekonomskih aktivnosti na globalnom nivou.

Mnogi preduzetnici suočili su se sa značajnim smanjenjem prihoda usled uticaja na globalni lanac snabdevanja robom i uslugama. Covid-19 je prouzrokovao brojne poremećaje u nacionalnim ekonomijama i postavio brojne izazove vezane za upravljanje $\mathrm{i}$ organizovanje poslovanja u ovakvim okolnostima.

$U$ vreme pandemije, i preduzetnici se moraju suočiti sa novom stvarnošću: pandemija COVID-19 nije samo ogromna sanitarna i zdravstvena kriza koja pogađa milione, pa čak i milijarde ljudi širom sveta, već takođe izaziva neviđeni pad globalne ekonomije. Postoji nekoliko načina na koje pandemija koronavirusa utiče na ekonomiju, posebno na preduzetnike, mala i srednja preduzeća, kako na strani ponude tako i na strani potražnje. Na strani ponude, kompanije doživljavaju smanjenje ponude radne snage, jer je radnicima loše ili moraju da se brinu o deci ili drugim izdržavanim licima dok su škole zatvorene i kretanje ljudi je ograničeno. Mere za suzbijanje bolesti zaključavanjem i karantinom dovode do daljeg i ozbiljnijeg smanjenja iskorišćenja kapaciteta. Dalje, lanci snabdevanja su prekinuti što dovodi do nestašice opreme, delova i repromaterijala. Covid-19 je stvorio probleme poput kratkoročnog i dugoročnog poštovanja rokova (Maritz et al., 2020). Na strani potražnje, dramatičan i nagli gubitak potražnje i prihoda za MSPP ozbiljno utiče na njihovu sposobnost da funkcionišu i/ili uzrokuje ozbiljne probleme u likvidnosti ovih preduzeća. Pored toga, i potrošači su suočeni sa gubitkom prihoda, strahom od zaraze i povećanom neizvesnošću, što zauzvrat smanjuje potrošnju. Svi ovi efekti su veoma složeni i međusobno povezani, jer se radnici otpuštaju, a firme nisu u mogućnosti da isplaćuju zarade. Neki sektori, poput turizma, sportskog turizma i saobraćaja, su posebno pogođeni, jer je u ovim sektorima drastično smanjen obim poslovanja. Mnoge sportske organizacije su bankrotirale, a pojedini sportisti izgubili izvor prihoda (Đurović i dr., 2020). Generalno, MSPP sektor je ranjiviji na „socijalno distanciranje“ od drugih kompanija. Dugoročno gledano, mnogim preduzećima će biti teško da obnove veze sa bivšim mrežama dobavljača, nakon što se naruše lanci snabdevanja i bivši partneri uspostave nove saveze i poslovne ugovore. Preduzeća, uključujući MSPP, snosiće najveći teret smanjenja globalne potražnje za svojim proizvodima i uslugama. Zbog preventivnih postupaka koje su preduzele vlade mnogih zemalja, brojna mala preduzeća, novoosnovana preduzeća i preduzetnici postali su najosetljivije grupe na koje utiče kriza koju je prouzrokovala pandemija (Ratten, 2020).

U ovakvim uslovima poslovanja, da bi opstala i izborila se sa postojećom krizom, malim i srednjim preduzećima je neophodan veoma sposoban menadžment i preduzetnici koji će u poslovanju primeniti nove modele upravljanja. Kako osnivačima preduzeća (preduzetnicima), tako i menadžerima trebaće vrlo različiti akcioni planovi u zavisnosti od sektora i industrije u kojoj posluju. Za one koji se bave internet trgovinom, dostavom hrane, video igrama ili video konferencijama, gde posao trenutno cveta, potpuno je drugačija slika nego za one koji posluju u oblasti hotelijerstva, ugostiteljstva, maloprodaji, zabavi ili sportu.

Pre svega su menadžerima neophodna znanja iz oblasti upravljanja rizikom, organizacionim promenama, a možda sada najbitnije, veštine upravljanja ljudskim resursima. Pandemija ima veliki utcaj na ljudske živote te kako bi in zaštitili mnogi poslodavci su primorani da promene ustaljene rutine i načine obavljanja posla. Jedan od tih načina predstavlja i rad od kuće, što za mnoge zaposlene predstavlja novinu, 
pa je od suštinskog značaja da ih menadžeri u tome podrže, motivišu i ukažu na značaj ovih promena koje su neizbežne. Takođe su važne inovacione sposobnosti menadžmenta, što pokazuju mnoge firme koje su u svoje poslovanje tokom pandemije unele korenite promene. U nekim preduzećima primećen je porast preduzetničke aktivnosti (Back et al., 2020). Naime, mnogi preduzetnici preusmerili su svoje poslovne strategije na proizvodnju proizvoda za kojima je veća potražnja. Proizvodnja ove robe je osnovna strategija opstanka i prilika za rast ovih preduzeća (Sedlaček, Šterk, 2020).

1. IZVORI PODATAKA I METODE PRIKUPLJANJA I DATA SOURCES AND COLLECTION METHODS

Za istraživanje uticaja COVID-19 na poslovanje preduzetnika, malih i srednjih preduzeća, kao i za istraživanje uticaja pandemije na proces upravljanja ovim preduzećima korišćeni su internet izvori, sekundarni podaci, kao i publikacije objavljene u naučnim časopisima tokom 2020. godine. Indikacije o uticaju epidemije COVID-19 na MSPP sektor dobijaju se putem anketa, koje periodično sprovode udruženja MSPP, istraživački centri, privredne komore ili banke. Različiti izveštaji koji su sačinjeni kao rezultat ovih istraživanja takođe su korišćeni kao izvori podataka u radu. Dobijeni rezultati su interpretirani u nastavku, tekstualno i u obliku tabela.

\section{REZULTATI I DISKUSIJA / RESULTS AND DISCUSSION}

Dokazi o uticajima krize COVID-19 na preduzetnike, mala i srednja preduzeća iz poslovnih anketa ukazuju na ozbiljne poremećaje i zabrinutost među malim preduzećima. U tabeli 1. predstavljeni su rezultati različitih anketa o preduzetnicima, malim i srednjim preduzećima i uticajima COVID-19 na njih koji su identifikovani širom sveta (https://portal.census.gov/pulse/data/, https://www.ifo.de/en/node/56337, https://www.japantimes.co.jp/opinion/2020/05/11/co mmentary/japan-commentary/will-happeninclusion-covid-19s-wake/, https://www.statista.com/statistics/1126870/hungarysmes-business-plan-after-covid-19/).

Tabela 1 - Uticaj COVID 19 na mala i srednja preduzeća, 2020

Table 1 - Impact of COVID 19 on SMEs in 2020

\begin{tabular}{|c|c|c|}
\hline Datum & Država & Uticaj na poslovanje \\
\hline 10 Feb. & Kina & $80 \%$ MSP još uvek nije nastavilo sa radom \\
\hline Početak Marta & Italija & $72 \%$ preduzeća direktno pogođeno \\
\hline Početak Marta & Velika Britanija & $63 \%$ preduzeća krizu vidi kao ozbiljnu pretnju za poslovanje \\
\hline 9 Mart & Nemačka & $50 \%$ preduzeća očekuje negativan uticaj \\
\hline 12 Mart & Velika Britanija & $69 \%$ preduzeća ima ozbiljnih problema sa novčanim tokovima \\
\hline 17 Mart & SAD & $\begin{array}{l}50 \% \text { preduzeća direktno negativno pogođeno, } 75 \% \text { veoma } \\
\text { zabrinuto }\end{array}$ \\
\hline 18 Mart & Belgija & $75 \%$ preduzeća izveštava o padu prometa \\
\hline 20 Mart & Holandija & $\begin{array}{l}50 \% \text { novoosnovanih preduzeća zabeležilo je značaje gubitke } \\
\text { u prihodima }\end{array}$ \\
\hline 21 Mart & Japan & Na 92\% preduzeća pandemija ima ekonomski uticaj \\
\hline 3 April & Belgija & $40 \%$ kompanija ima pad prihoda od $75 \%$ ili više \\
\hline 7 April & Kanada i SAD & Oštećeno $90 \%$ malih preduzeća \\
\hline 24 April & Nemačka & $58 \%$ MSP doživljava pad prometa u proseku za $50 \%$ \\
\hline 11 Maj & SAD & $81 \%$ firmi očekuje uticaj pandemije i u narednih $12-16$ meseci \\
\hline
\end{tabular}

Obrada autora

Primeri ankete u Tabeli 1. predstavljeni su hronološkim redosledom i pokazuju sve veću zabrinutost među MSPP. Rezultati istraživanja na preko 5.800 malih preduzeća u Sjedinjenim Državama pokazali su da je u prvim mesecima pandemije $43 \%$ preduzeća privremeno zatvoreno. U proseku su preduzeća smanjila svoje zaposlene za $40 \%$. Tri četvrtine od ispitanih preduzeća navelo je da rezervi imaju za dva meseca ili manje. Prema istraživanju Međunarodnog trgovinskog centra (International
Trade Centre) među malim i srednjim preduzećima u 132 zemlje, dve trećine mikro i malih preduzeća izveštava da je kriza snažno uticala na njihovo poslovanje, a jedna petina ukazuje na rizik trajnog gašenja u roku od tri meseca (ITC, 2020). Istraživanja u pojedinim zemljama, (McKinsey, 2020) ukazala su da bi se između $25 \%$ i $36 \%$ malih preduzeća moglo trajno zatvoriti od poremećaja u poslovanju izazvanih pandemijom u prva četiri meseca. 
Tabela 2 - Pregled publikacija o uticaju COVID-19 na MSPP

Table 2 - Review of publications on the impact of COVID-19 on SMES

\begin{tabular}{|c|c|c|}
\hline Publikacija & Predmet istraživanja & Rezultati \\
\hline $\begin{array}{l}\text { Meahjohn, I., \& } \\
\text { Persad, P. (2020). }\end{array}$ & $\begin{array}{l}\text { Uticaj COVID-19 na } \\
\text { preduzetništvo na globalnom } \\
\text { nivou }\end{array}$ & $\begin{array}{l}\text { Smanjenje potražnje; Prekidi u lancima } \\
\text { snabdevanja i kanalima distribucije; } \\
\text { Smanjena potražnja investitora }\end{array}$ \\
\hline $\begin{array}{l}\text { Bartik, A. W., Bertrand, } \\
\text { M., Cullen, Z., Glaeser, } \\
\text { E. L., Luca, M., \& } \\
\text { Stanton, C. (2020). }\end{array}$ & $\begin{array}{l}\text { Uticaj COVID-19 na ishode } \\
\text { malih preduzeća i očekivanja }\end{array}$ & $\begin{array}{l}\text { Masovna otpuštanja i zatvaranja; } \\
\text { Nedostatak finansijskih sredstava i } \\
\text { kreditno zaduživanje }\end{array}$ \\
\hline $\begin{array}{l}\text { Zou, P., Huo, D., \& Li, } \\
\text { M. (2020). }\end{array}$ & $\begin{array}{l}\text { Uticaj pandemije COVID-19 } \\
\text { na firme: istraživanje u } \\
\text { provinciji Guangdong, Kina }\end{array}$ & $\begin{array}{l}\text { Zastoj u radu i zatvaranje; Prelaz na e- } \\
\text { trgovinu i rad od kuće; Smanjenje } \\
\text { proizvodnje i pad produktivnosti }\end{array}$ \\
\hline $\begin{array}{l}\text { Fabeil, N. F., Pazim, K. } \\
\text { H., \& Langgat, J. } \\
\text { (2020). }\end{array}$ & $\begin{array}{l}\text { Uticaj pandemije COVID-19 } \\
\text { na mikropreduzeća }\end{array}$ & Zatvaranje preduzeća; Smanjeni prihodi \\
\hline $\begin{array}{l}\text { Liñán, F., \& Jaén, l. } \\
\text { (2020). }\end{array}$ & $\begin{array}{l}\text { Pandemija COVID-19 i } \\
\text { preduzetništvo }\end{array}$ & $\begin{array}{l}\text { Negativan uticaj na preduzetništvo; } \\
\text { Opadajući trend preduzetničkih aktivnosti; } \\
\text { Uz podršku okoline i insitucija moguć } \\
\text { procvat preduzetništva }\end{array}$ \\
\hline Syriopoulos, K. (2020). & $\begin{array}{l}\text { Uticaj COVID-19 na } \\
\text { preduzeztništvo i MSP }\end{array}$ & $\begin{array}{l}\text { Pad potražnje za robom i uslugama; } \\
\text { Nedostatak sredstava, smanjena } \\
\text { likvidnost; Zatvaranje preduzeća }\end{array}$ \\
\hline $\begin{array}{l}\text { Brown, R., \& Rocha, A. } \\
\text { (2020). }\end{array}$ & $\begin{array}{l}\text { Preduzetnička neizvesnost } \\
\text { tokom krize COVID-19 }\end{array}$ & $\begin{array}{l}\text { Novoosnovana preduzeća najteže } \\
\text { pogođena krizom; Smanjenje ukupnog } \\
\text { obima investicija; Preduzetnički izvori } \\
\text { finansiranja nisu dostupni }\end{array}$ \\
\hline $\begin{array}{l}\text { Donthu, N., \& } \\
\text { Gustafsson, A. (2020). }\end{array}$ & $\begin{array}{l}\text { Efekti COVID-19 na } \\
\text { poslovanje i istraživanje }\end{array}$ & $\begin{array}{l}\text { Promene u ponašanju preduzeća i } \\
\text { ponašanju potrošača; Nedostaci u } \\
\text { pogledu tehnološke spremnosti; } \\
\text { Redizajniranje lanca snabdevanja; } \\
\text { Društvena i ekološka održivost }\end{array}$ \\
\hline Ratten, V. (2020). & $\begin{array}{l}\text { Koronavirus (Covid-19) i } \\
\text { preduzetništvo: kulturne, } \\
\text { životne i društvene promene }\end{array}$ & $\begin{array}{l}\text { Podsticanje volonterskih aktivnosti; } \\
\text { Promena načina obavljanja posla; } \\
\text { Neophodnost podrške socijalnim } \\
\text { preduzetnicima; Neophodnost razvoja } \\
\text { kulture deljenja }\end{array}$ \\
\hline $\begin{array}{l}\text { Beraha, I., \& Đuričin, } \\
\text { S. (2020). }\end{array}$ & $\begin{array}{l}\text { Uticaj COVID-19 pandemije } \\
\text { na srednja preduzeća u Srbiji }\end{array}$ & $\begin{array}{l}\text { Zabrinutost za zdravlje zaposlenih; } \\
\text { Zabrinutost za nedostatak sredstava i } \\
\text { potencijalni gubitak tržišnog udela; Uticaj } \\
\text { na poslovnu aktivnost; Veća otpornost na } \\
\text { negativne uticaje krize u odnosu na mikro i } \\
\text { mala preduzeća }\end{array}$ \\
\hline
\end{tabular}

U tabeli 2. prikazan je pregled odabranih publikacija u kojima je istraživan uticaj COVID-19 na preduzetnike, mala i srednja preduzeća. Na osnovu pregleda odabraih publikacija može se videti da je istraživanje uticaja pandemije na preduzetništvo veoma aktuelna tema u naučnoj javnosti. Međutim, kada je u pitanju Srbija, uvidom u dostupne izvore podataka, pronađena je samo jedna publikacija na ovu temu, u kojoj su istraživanjima obuhvaćena samo srednja preduzeća. U inostranoj literaturi, autori su istraživali uticaj pandemije kako na globalnom, tako i na lokalnom nivou. Istraživanjima su obuhvaćena mikro, mala i srednja preduzeća, analizirani su ishodi poslovanja ovih preduzeća, njihova očekivanja, kulturne, organizacione i društvene promene u njima tokom pandemije. Rezultati ovih istraživanja pokazuju slične ishode na globalnom nivou. Naime, "zaključavanje" država izazvalo je smanjenje potražnje za određenim proizvodima i uslugama, prekide u lancima snabdevanja i kanalima distribucije, smanjenje nivoa investicija. Sve to dovelo je do smanjenja proizvodnje i pada produktivnosti, smanjene likvidnosti, nedostatka finansijkih sredstava i kreditnog zaduživanja. 
Navedeni problem uslovili su pad preduzetničkih aktivnosti a u velikom broju slučajeva i zatvaranje preduzeća. Sa druge strane, javlja se potreba za volonterskim aktivnostima, neophodna je promena načina poslovanja kao i podrška socijalnim preduzetnicima i razvoj kulture "deljenja". Rezultati istraživanja sprovednih u Srbiji se umnogome poklapaju sa rezultatima istraživanja sprovedenim u svetu i takođe ukazuju da pandemija ima veliki uticaj na poslovne aktivnosti, da su menadžeri zabrinuti za zdravlje zaposlenih kao i za nedostatak sredstava i potencijalni gubitak tržišta. Ipak, srednja preduzeća su pokazala otpornost na negativne uticaje krize u odnosu na mikro i mala preduzeća.

Tabela 3 - Pregled publikacija o upravljanju tokom pandemije COVID-19

Table 3 - Review of publications on enterprise management during the pandemic

\begin{tabular}{|l|l|l|}
\hline \multicolumn{1}{|c|}{ Publikacija } & \multicolumn{1}{|c|}{ Predmet istraživanja } & \multicolumn{1}{c|}{ Rezultati } \\
\hline $\begin{array}{l}\text { Carnevale, J. B., \& } \\
\text { Hatak, I. (2020). }\end{array}$ & $\begin{array}{l}\text { Implikacije za upravljanje } \\
\text { ljudskim resursima tokom } \\
\text { pandemije }\end{array}$ & $\begin{array}{l}\text { Nagle promene u društvenoj strukturi radnog } \\
\text { okruženja; Nove prakse socijalizacije, } \\
\text { virtuelni ručkovi, pauze za kafu I dr.; } \\
\text { Organizaciona podrška zaposlenima za } \\
\text { postizanje ravnoteže porodica - posao }\end{array}$ \\
\hline $\begin{array}{l}\text { Opatha, H. H. D. N. P. } \\
\text { (2020). }\end{array}$ & $\begin{array}{l}\text { Korona virus i zaposleni - } \\
\text { upravljanje ljudskim } \\
\text { resursima }\end{array}$ & $\begin{array}{l}\text { Osiguranje zaštite zdravlja zaposlenih; } \\
\text { Osiguranje nesmetanog odvijanja operacija } \\
\text { u organizaciji; Dobre organizacione } \\
\text { sposobnosti }\end{array}$ \\
\hline $\begin{array}{l}\text { Dirani, K. M., Abadi, } \\
\text { B., Alizadeh, A., } \\
\text { C., Gunase, B., Garza, R. } \\
\text { Majzun, Z. (2020). }\end{array}$ & $\begin{array}{l}\text { Kompetencije lidersvta i } \\
\text { upravljanje ljudskim } \\
\text { resursima u doba pandemije }\end{array}$ & $\begin{array}{l}\text { Redovno informisanje zaposlenih, } \\
\text { komunikacija sa zaposlenima i sa } \\
\text { menadžerima nižih nivoa, smanjenje stersa } \\
\text { kod zaposlenih, prepoznavanje straha i } \\
\text { psihološko osnaživanje zaposlenih; } \\
\text { Fleksibilnost }\end{array}$ \\
\hline Vnoučková, L. (2020). & $\begin{array}{l}\text { Uticaj COVID-19 na } \\
\text { upravljanje ljudskim } \\
\text { resursima }\end{array}$ & $\begin{array}{l}\text { Upravljanje na daljinu i nove kompetencije } \\
\text { menadžera; Motivacija i podrška } \\
\text { zaposlenima; Brzo prilagođavanje } \\
\text { promenama i promena planova; Upotreba } \\
\text { savremenih tehnologija; Online sastanci; } \\
\text { Obezbeđivanje obuke zaposlenih }\end{array}$ \\
\hline Gigauri, I. (2020). & $\begin{array}{l}\text { Efekti COVID-19 na } \\
\text { upravljanje ljudskim } \\
\text { resursima iz perspektive } \\
\text { digitalizacije }\end{array}$ & $\begin{array}{l}\text { Pružiti mogućstvo zaposlenima da biraju } \\
\text { način rada; Stvaranje nove organizacione } \\
\text { kulture; Stvaranje digitalnih kancelarijskih } \\
\text { prostora; Edukacija zaposlenih }\end{array}$ \\
\hline $\begin{array}{l}\text { Upravljanje tokom COVID- } \\
\text { 19 pandemije }\end{array}$ & $\begin{array}{l}\text { Orijentacija na sve zainteresovane strane; } \\
\text { Saradnja sa zajednicom, dobavljačima, } \\
\text { kupcima; Upotreba IT tehnologija }\end{array}$ \\
\hline Sheth, J. (2020). & Promena poslovnih modela & $\begin{array}{l}\text { Dinamičke sposobnosti; Sposobnosti } \\
\text { prilagođavanja; Povećanje stepena } \\
\text { digitalizacije }\end{array}$ \\
\hline
\end{tabular}

U tabeli 3. prikazan je pregled odabranih publikacija u kojima je istraživan uticaj pandemije na prces upravljanja i problemi sa kojima se menadžeri u procesu upravljanja susreću tokom pandemije. $\mathrm{Na}$ osnovu pregleda odabraih publikacija može se videti da pandemija najviše ima uticaja na jednu posebnu oblast upravljanja - na upravljanje ljudksim resursima. Autori su uglavnom istraživali kompetencije lidera i menadžera za upravljanje ljudskim resursima tokom pandemije, efekte pandemije na upravljanje ljudskim resursima iz perspektive digitalizacije, implikacije za upravljanje ljudskim resursima tokom pandemije, kao i neophodnost promene poslovnih modela. Rezultati pokazuju slične ishode na globalnom nivou. Dakle, pandemija je prouzrokovala nagle promene u društvenoj strukturi i radnom okruženju, što zahteva veliku sposobnost prilagođavanja ovim promenama, uvođenje novih praksi socijalizacije, redovno informisanje zaposlenih i komunikacija sa njima. Pandemija i socijalno distanciranje umnogome utiče i na psihičko stanje zapsolenih, pa im je potrebna motivacija i podrška. Svuda gde je to moguće uvodi se rad na daljinu stvaranjem takozvanih "digitalnih kancelarija", održavaju se online sastanci, što zahteva upotrebu IT tehnologija i dodatnu edukaciju zaposlenih za 
ovakvu vrstu posla. Sve ovo ukazuje da je za menadžere od najvećeg značaja posedovanje međuljudskih veština, jer da bi se navedeni problemi prevazišli neophodno je pre svega stvaranje nove organizacione kulture preduzeća, uvođenjem novin načina rada i novih poslovnih modela. Uvidom u dostupne izvore podataka, nije pronađena ni jedna publikacija koja se bavi ovom problematikom u Srbiji.

Vredi napomenuti $\mathrm{i}$ to da pandemija virusa COVID-19, pored uticaja na preduzetništvo, umnogome utiče i na životnu sredinu, i to na više različitih načina. Sa jedne strane je pozitivan uticaj, koji se video samo par meseci nakon što je čovek poštedeo prirodu od svog punog uticaja. Tada su na milijardama ekrana širom sveta počele da se pojavljuju slike bistre vode Kanala u Veneciji, životinja koje osvajaju svoja izgubljena staništa i dr. (Lukinović, Jovanović, 2020). Međutim, sa druge strane, svedoci smo da svuda oko nas, pored postavljenih kanti za otpatke, na ulici, stazama i zelenim površinama, možemo videti bačene iskorišćene maske i rukavice. Opasnost od ovakvog ponašanja leži u tome što ova zaštitna oprema posle upotrebe postaje potencijalni infektivni otpad. Sve ovo može da bude izazov kako za menadžere u oblasti zaštite životne serdine, tako i za menadžere privrednih preduzeća. Naime, fantastične slike bistre vode i gradova bez magle i smoga, trebale bi da podstaknu menadžere preduzeća da još više uvide značaj "čistog" poslovanja i shvate da je neophodno pronaći nove modele ekonomskog rasta i razvoja koji neće ugrožavati životnu sredinu, a koji će doprineti unapređenju kvaliteta života (Mihajlović i dr., 2020). Takođe, zastrašujuće slike velike količine otpada bi mogle da podstaknu preduzetnike na pokretanje novog biznisa, reciklaže, koja je preko potrebna i životnoj sredini koja bi tako postala čistija, a samim preduzetnicima, jer bi ostvarili prihode $u$ ovako kriznim situacijama.

\section{ZAKLJUČAK / CONCLUSION}

Globalna vanredna zdravstvena situacija proglašena 11. marta 2020. godine zahvatila je stotine hiljada života širom sveta, predstavljajući izazov za zdravstvene radnike. Pored uticaja na ljudske živote, ova pandemija je u velikoj meri uticala na preduzetničko poslovanje. Istraživanja su pokazala da mala i srednja preduzeća sve više doživljavaju uticaj krize. Zbog preventivnih mera koje su vlade preduzele da ograniče i spreče prenos virusa, došlo je do ogromnih socijalnih i ekonomskih poremećaja u preduzetništvu. Krizom su najteže pogođena novoosnovana preduzeća. Pad preduzetničkih aktivnosti, otpuštanje radnika i zatvaranje preduzeća uočava se na globalnom nivou. Istraživanja su pokazala da se i preduzeća u Srbiji suočavaju sa sličnim problemima kao preduzeća na globalnom nivou. Za rešavanje problema koje je prouzrokovala pandemija neophodno je uvođenje novih poslovnih modela, a menadžerima su neophodne međuljudske veštine, kao i organizacione i inovativne sposobnosti, kako bi postojeće pretnje pretvorili u šanse, preusmerili svoje poslovanje i nastavili sa obavljanjem preduzetničkih aktivnosti.

\section{LITERATURA / REFERENCES}

[1] Bacq, S., Geoghegan, W., Josefy, M., Stevenson, R., \& Williams, T. A. (2020). The COVID-19 Virtual Idea Blitz: Marshaling social entrepreneurship to rapidly respond to urgent grand challenges. Business Horizons, 63(6), 705-723.

[2] Bartik, A. W., Bertrand, M., Cullen, Z., Glaeser, E. L., Luca, M., \& Stanton, C. (2020). The impact of COVID-19 on small business outcomes and expectations. Proceedings of the National Academy of Sciences, 117(30), 17656-17666.

[3] Beraha, I., \& Đuričin, S. (2020). The impact of COVID-19 crisis on medium-sized enterprises in Serbia. Economic Analysis, 53(1), 14-27.

[4] Brown, R., \& Rocha, A. (2020). Entrepreneurial uncertainty during the Covid-19 crisis: Mapping the temporal dynamics of entrepreneurial finance. Journal of Business Venturing Insights, 14, e00174.

[5] Carnevale, J. B., \& Hatak, I. (2020). Employee adjustment and well-being in the era of COVID19: Implications for human resource management. J. Business Research, 116, 183-187.

[6] Dirani, K. M., Abadi, M., Alizadeh, A., Barhate, B., Garza, R. C., Gunasekara, N., ... \& Majzun, Z. (2020). Leadership competencies and the essential role of human resource development in times of crisis: a response to Covid-19 pandemic. Human Resource Development International, 23(4), 380-394.

[7] Donthu, N., \& Gustafsson, A. (2020). Effects of COVID-19 on business and research. Journal of business research, 117, 284.

[8] Đurović, S., Perović, A., Šiljak, V., Antonijević, S., Veselinović, J., Baćevac, S. (2020). Održivost razvoja sporstkog turizma kao privredne grane: uticaj COVID-19, Ecologica, 27(100), 699-706.

[9] Fabeil, N. F., Pazim, K. H., \& Langgat, J. (2020). The impact of Covid-19 pandemic crisis on microenterprises: Entrepreneurs' perspective on business continuity and recovery strategy. Journal of Economics and Business, 3(2). 
[10] Gigauri, I. (2020). Effects of covid-19 on human resource management from the perspective of digitalization and work-life-balance. International Journal of Innovative Technologies in Economy, 4 (31).

[11] https://portal.census.gov/pulse/data/

[12] https://www.ifo.de/en/node/56337,

[13] https://www.statista.com/statistics/1126870/hung ary-smes-business-plan-after-covid-19/

[14] https://www.japantimes.co.jp/opinion/2020/05/11 /commentary/japan-commentary/will-happeninclusion-covid-19s-wake/

[15] ITC, 2020; https://www.intracen.org/itc/marketinfo-tools/trade-statistics/

[16] Keni, Raghuvir, Anila Alexander, Pawan Ganesh Nayak, Jayesh Mudgal, and Krishnadas Nandakumar (2020). COVID-19: Emergence, Spread, Possible Treatments, and Global Burden. Frontiers in public health, 8: 216.

[17] Kuckertz, A., Brandle, L., Gaudig, A., Hinderer, S., Reyes, C. A M., Prochotta, A., Steinbrink, K., \& Berger, E.S.C. (2020). Startups in times of crisis - A rapid response to the COVID-19 pandemic. Journal of Business Venturing Insights, e00169.

[18] Liguori, E., Winkler, C. (2020). From Offline to Online: Challenges and Opportunities for Entrepreneurship Education Following the COVID-19 Pandemic. SAGE Publications, Sage CA: Los Angeles, CA.

[19] Liñán, F., \& Jaén, I. (2020). The Covid-19 pandemic and entrepreneurship: some reflections. International Journal of Emerging Markets, 10.

[20] Liu, Yipeng, Jong Min Lee, Celia Lee (2020). The challenges and opportunities of a global health crisis: the management and business implications of COVID-19 from an Asian perspective. Asian Business \& Management, 19, 277-297.

[21] Lukinović, M., Jovanović, L. (2020). Uticaj pandemije COVID-19 na životnu sredinu, Ecologica, 27(99), 376-382.

[22] Maritz, A., Perenyi, A., de Waal, G., \& Buck, C. (2020). Entrepreneurship as the Unsung Hero during the Current COVID-19 Economic Crisis: Australian Perspectives. Sustainability 12 (11): 4612.

[23] McKinsey and Company. (2020). The near-term impact of coronavirus on workers. Retrieved April 6, 2020, from

https://www.mckinsey.com/industries/publicsector/our-insights/lives-and-livelihoods- assessing-the-near-termimpact-of-covid-19-onus-workers?

[24] Meahjohn, I., \& Persad, P. (2020). The Impact of COVID-19 on Entrepreneurship Globally. Journal of Economics and Business, 3(3).

[25] Mihajlović, D., Jovanović, V., Stojanović, D. (2020). Doprinos obnovljivih izvora energije razvoju zelene ekonomije i održive industrije, Ecologica, 27(98), 180-186.

[26] Opatha, H. H. D. N. P. (2020). The Coronavirus and The Employees: A Study from the Point of Human Resource Management. Sri Lankan Journal of Human Resource Management, 10(1), 37-49.

[27] Ratten, V. (2020). Coronavirus (Covid-19) and entrepreneurship: cultural, lifestyle and societal changes. Journal of Entrepreneurship in Emerging Economies. Ahead-of-print

[28] Ratten, V. (2020). Coronavirus (Covid-19) and entrepreneurship: changing life and work landscape. Journal of Small Business, and Entrepreneurship, 32(5), 503-516.

[29] Sedlacek, P., Sterk, V. (2020). Startups and Employment Following the COVID-19 Pandemic: A Calculator. Retrieved May 6, 2021, from https://voxeu.org/article/startup-employmentcalculator-covid-19

[30] Seetharaman, P. (2020). Business models shifts: Impact of Covid-19. International Journal of Information Management, 54, 102173.

[31] Sheth, J. (2020). Business of business is more than business: Managing during the Covid crisis. Industrial Marketing Management, 88, 261-264.

[32] Syriopoulos, K. (2020). The impact of COVID-19 on entrepreneurship and SMEs. Journal of the International Academy for Case Studies, 26(2), 1-2.

[33] Vaccaro, A.R., Getz, C.L., Cohen, B.E., Cole, B.J., \& Donnally, C.J. III. (2020). Practice management during the COVID-19 pandemic. Journal of American Academy of Orthopaedic Surgeons.

[34] Vassileva, A., Simić, M., Stevanović, M. (2020) Implications of COVID-19 for international business. Ecologica, 27(100), 589-596.

[35] Vnoučková, L. (2020). Impact of COVID-19 on human resource management. Revista Latinoamericana de Investigación Social, 3(1), 18-21.

[36] Zou, P., Huo, D., \& Li, M. (2020). The impact of the COVID-19 pandemic on firms: a survey in Guangdong Province, China. Global health research and policy, 5(1), 1-10. 